Indian J Anim Health (2021), 60(1) : 31-39

DOI:10.36062/ijah.60.1.2021.31-39

\title{
Investigations on the need matrix of Primary Fishermen's Cooperative Societies in the district of North 24 Parganas, West Bengal
}

\begin{abstract}
R. Nasar ${ }^{1 *}$, S. K. Das ${ }^{2}$ and M. K. Pati ${ }^{1}$
${ }^{1}$ Department of Fishery Sciences, Vidyasagar University, Midnapore 721 102, West Bengal, India; ${ }^{2}$ Department of Aquaculture, West Bengal University of Animal and Fishery Sciences, Chakgaria, Kolkata 700 094, West Bengal, India

Abstract

The central objective of the formation of Fishermen's Cooperatives is to uplift the income, wellbeing and socioeconomic status of members through sustainable development and utilization of water resources under its possession. Primary Fishermen's Cooperative Societies (PFCSs) in West Bengal face diverse problems, impacting their internal functioning and thereby not yielding the desired outcomes of poverty alleviation of fisher folks and sustainable development of water bodies. Studies on fishermen's cooperatives in the state are limited and majority has focused on socio-economic status of its members, marketing channels involved and constraints faced by them. Under such circumstances, it is imperative to assess the need-based expectations of these cooperatives for necessary policy changes focused on strengthening them. The present paper reports the findings from the study undertaken for 39 functioning PFCSs in the district of North 24 Parganas, West Bengal, for delineating crucial need-based assistances, as perceived by office bearers of these societies, that can aid in improving the functioning of these societies towards augmentation of fish production and meeting the socio-economic aspirations of its members. Office bearers of PFCSs responded against pre-designed questionnaires assigned for their society through mutual consensus. The outcome of the study revealed that infrastructural support was viewed as the most important assistance needed by majority of PFCSs in the district. Financial support and welfare measures were jointly viewed as second major expected assistance by most of the PFCSs. Technical support was felt next in line with expected assistances followed by policy interventions at the end.
\end{abstract}

Key words: PFCS, Fishermen, Perceived assistances, Policy interventions

\section{INTRODUCTION}

Despite a notable increase in fish production from 14.43 lakh ton (LT) to 17.42 LT during 2010-11 to 2017-18, there has been a consistent deficit concerning fish production and demand in West Bengal. 2017-2018, recorded a deficit of (-) 0.42 LT (Department of Fisheries, 2019). For achieving the government's target of doubling fish production by 2023 and bridging the deficit gap, augmentation of fish production through optimum utilization of water resources and infrastructural and human resource development in the fisheries sector is imperative. Holistic planning for phase-wise intensification of fish culture in the state should include mobilization, monitoring and management of all the available water resources; especially the big water bodies of 5 acres and above, whose contribution towards the fish production is much below the optimum level. The majority of such water bodies are under the possession and management of Primary Fishermen's Cooperative Societies (PFCSs), which are not well organized and need strengthening. Fishery cooperatives are considered instrumental in increasing fish production, employment generation and amelioration of the socioeconomic condition of fishermen. The role of cooperatives in India as a tool for improving the socio-economic status of the fishermen community who at large are considered amongst the weakest in the society is well documented (D'cruz, 1998). Since there exists, ample opportunity in fish product exports, the fishery cooperatives can contribute to the national economy as well (Sapovadia, 2004).

The percentage area of water bodies under the possession of PFCSs in West Bengal accounts 
for $6.31 \%$ of the total impounded water system. However, their contribution in fish production basket accounts for a meager $3.30 \%$ (0.515 LT) of the total inland fish production of $15.57 \mathrm{LT}$ (Department of Fisheries, 2019). West Bengal has witnessed a significant increase in the number of fishery cooperatives over the years. Presently the state has 1215 fishery cooperatives with a recorded water area of 27153.62 ha and a membership of 131578 fisherfolks. However, the overall status of these societies is dismal as only $38 \%$ (i.e., 469) and $13 \%$ (i.e., 159) have been reported to be functional and semi-functional respectively; whereas, the remaining $49 \%$ fall under nonfunctional, not-interested and not-traceable categories (Directorate of Fisheries, 2017).

The overall performance of fishery cooperatives in India is not encouraging (Prakash, 2000). The major hindrances in achieving the desired outcome from fishermen's cooperatives can be attributed to poor management, lack of skill enhancement mechanism, discouraging productivity and production trends, inadequate infrastructure facilities, problematic finance management and poor linkages amongst concerned organizations (Planning Commission, 2002). Apart from these some inherent traits in the fishermen community, viz., lower educational levels, poverty, lack of political and social awareness, hinder the overall prospects of organized development of these societies. Lack of effective management was one of the prime factors for the collapse of the cooperative movement in the fisheries sector (Annamalai, 1996). Substantial increases in operational cost over the years, accompanied by a reduction in total fish catch are major impediments faced by many cooperative societies (Gopal et al., 2010). Shortage of quality fish seed is another detriment impacting overall productivity (De et al., 2012). Inaccessibility and lack of awareness of the latest technologies in aquaculture also posed a major hindrance in achieving the desired levels of production (Bhaumik et al., 1992). Identifying the constraints that hinder the growth of fishery cooperatives and addressing the expected assistances of appropriate stakeholders, will aid in providing genuine support to the underperforming cooperatives in a region.

Despite several prevailing government schemes in the fisheries sector, the PFCSs in the state are lagging in delivering their expected potential to achieve fish production and socio-economic changes. There is a need to recognize the unidentified gaps contributing to the differences between the desired outcomes from the implemented schemes to that of ground-level progress. One such gap can be addressed by taking into consideration the need perception of the target group. It is imperative to take into account the expected needs of PFCSs through the office bearers who are collectively responsible for the day to day functioning of the societies. Decisions on the culture practices adopted, social and economic reforms undertaken, impact the overall functioning of the societies. For strategizing short-term and long-term policies for PFCSs, need-based analysis is one of the key factors.

With this background, the present study aims to find out the expected need-based assistances of PFCSs to formulate a possible support extension mechanism that will aptly strengthen and better the performances of the fishermen's cooperatives in the fishery resourcerich district of North 24 Parganas in West Bengal. The results of the present study will assist in identifying the gaps, if any, between, the actual needs of PFCSs and the schemes being offered to them. Furthermore, it will aid in modifying the existing schemes, if required and framing future policies concerning the functioning of PFCSs that will aptly balance profit maximization, revenue earning, resource utilization and socio-economic uplifment of poor and downtrodden fisherfolks. It will also aid in designing and implementing sitespecific developmental projects for these societies to mitigate their constraints and help them resuscitate.

\section{MATERIALS AND METHODS Study Area and data collection}

The present study was carried out in the district of North 24 Parganas of West Bengal, India, which is located in the tropical zone from 
Table 1. Fishermen's Cooperatives in North 24 Parganas in 2016

\begin{tabular}{lcccc}
\hline $\begin{array}{l}\text { No. of } \\
\text { Co-ops }\end{array}$ & $\begin{array}{c}\text { No. of } \\
\text { members }\end{array}$ & $\begin{array}{c}\text { Recorded } \\
\text { water area (ha) }\end{array}$ & $\begin{array}{c}\text { Annual } \\
\text { turnover (Rs.) }\end{array}$ & $\begin{array}{c}\text { Table Fish } \\
\text { production (kg) }\end{array}$ \\
\hline $\begin{array}{c}74 \\
\text { (73 PFCSs+1 Central Fishermen's }\end{array}$ & 8072 & 1950.30 & 151200750 & 3417934 \\
Cooperative Society) & & & \\
\hline
\end{tabular}

(Directorate of Fisheries, 2017)

latitude $22^{\circ} 11^{\prime} 6^{\prime \prime}-23^{\circ} 15^{\prime} 2^{\prime \prime} \mathrm{N}$ and longitude $88^{\circ} 20^{\prime}-89^{\circ} 5^{\prime}$ E. The selection of district was based on the fact that with a total of 73 PFCSs (40 Functional, 12 Semi Functional, 15 NonFunctional, 6 Not traceable), North 24 Parganas is one of the forerunners in terms of the existence of active registered fishermen cooperative societies in the state (Table 1). Fisheries occupy a significant place in the economy and livelihood of people in the district, as it is endowed with diverse water resources viz., impounded freshwater including beels and baors (26008 ha), sewage-fed fishery (1560.35 ha) and brackishwater (35371 ha) (Department of Fisheries, 2019). The total fish production of the district was 206983 metric ton (MT) in 201718 , ranking third amongst all the districts in West Bengal (Department of Fisheries, 2019), corroborating the importance of aquaculture and fishery enterprises in the region.

The study was conducted for one year during 2018-19 and was based on the collected data from primary sources via field surveys and secondary data from reports of Govt. of West Bengal. For the present investigation only functional PFCSs were taken into consideration. Out of the total 40 functional PFCSs, data were collected from 39, since the only ornamentalfisheries cooperative society in the district was not considered for the present study. Depending on the kind of water bodies under the possession of PFCSs, they were grouped as freshwater $(n=28)$, brackishwater $(n=7)$ and sewage-fed $(n=4)$ societies. The office-bearers of these societies were interviewed with the help of a pretested, structured questionnaire in the local language to gather primary data. Each society was assigned with a single questionnaire and the responses through the office bearers were collectively reflected through mutual consensus against the single questionnaire for that particular PFCS. Each PFCS was treated as a single unit of sample, making the sample size for freshwater, brackishwater and sewage-fed PFCSs as 28, 7 and 4, respectively, thereby comprising 39 samples $(\mathrm{N}=39)$ in total.

\section{Variables and their measurement}

The possible expected need-based assistance that will enable the societies to do better their performances in terms of fish production, management and overall functioning were collected from the office bearers in each of the functional PFCSs through a pre-designed schedule comprising of open-ended questions. The collected information was then systematically grouped under different categories and sub-categories of expected assistances and eventually analyzed by using suitable statistical tools. The five broad expected areas of assistance were categorized as Financial, Technical, Infrastructural, Welfare and Policy interventions. Each category was further subdivided into different aspects of the expected assistance (Table 2).

To measure the intensity of these expectations $v i s$ - $a$-vis their relative importance, item-wise frequency table was used. Based on the total frequency, the intensity of the need was calculated and categories of assistance along with the subcategories were ranked accordingly to develop a need matrix. The calculation of the intensity of need from the available frequency and population of PFCS was developed for the present study. Intensity of need $=$ Total frequency/Population wherein, population means the number of PFCS

\section{RESULTS}

Financial assistance

The intensity of need for financial 
Table 2. Categories of assistances expected by PFCSs

\begin{tabular}{lllll}
\hline \multicolumn{1}{c}{ Financial } & Technical & Infrastructural & Welfare & \multicolumn{1}{c}{$\begin{array}{c}\text { Policy } \\
\text { interventions }\end{array}$} \\
\hline $\begin{array}{l}\text { Easy accessibility } \\
\text { to bank loans }\end{array}$ & $\begin{array}{l}\text { Dissemination of } \\
\text { technology } \\
\text { through training }\end{array}$ & $\begin{array}{l}\text { Renovation and } \\
\text { reclamation of } \\
\text { water bodies }\end{array}$ & Housing schemes & Lease rent fixation \\
$\begin{array}{l}\text { Bank loan at a } \\
\text { lower rate of }\end{array}$ & $\begin{array}{l}\text { Availability of } \\
\text { quality fish seed } \\
\text { interest }\end{array}$ & $\begin{array}{l}\text { Construction of } \\
\text { office and } \\
\text { and feed }\end{array}$ & Old-age pension & $\begin{array}{l}\text { Strengthening of } \\
\text { marketing channel }\end{array}$ \\
Managerial subsidy & $\begin{array}{l}\text { Physicochemical } \\
\text { analysis of soil }\end{array}$ & $\begin{array}{l}\text { Establishment } \\
\text { of hatchery }\end{array}$ & $\begin{array}{l}\text { Health insurance } \\
\text { scheme }\end{array}$ & $\begin{array}{l}\text { Assured market } \\
\text { prices }\end{array}$ \\
$\begin{array}{l}\text { and water } \\
\text { Financial assistance }\end{array}$ & $\begin{array}{l}\text { Easy access to } \\
\text { disease diagnostic } \\
\text { schernemes }\end{array}$ & $\begin{array}{l}\text { Other } \\
\text { infrastructural } \\
\text { facility }\end{array}$ & $\begin{array}{l}\text { Provident Fund } \\
\text { like landless } \\
\text { agricultural labourers }\end{array}$ & Crop insurance \\
\hline
\end{tabular}

assistance was maximum in the case of sewagefed societies followed by brackishwater and then freshwater PFCSs (Table 3). Amongst the subcategories, managerial subsidy recorded the highest frequency for freshwater societies. Brackishwater societies registered easy access to bank loans as the topmost expected financial help. For the sewage-fed societies the most prioritized financial help was that of financial assistance under govt. schemes.

\section{Technical assistance}

Frequency data for expected technical assistance (Table 3) revealed that the availability of quality fish seed and feed is the most preferred technical support for freshwater and sewage-fed fishery societies of the district. For brackishwater societies access to disease diagnostic centre was the most wanted technical support. Physicochemical analysis of soil and water and access to disease diagnostic centre recorded the same level of intensity of need for the sewage-fed societies.

\section{Infrastructural assistance}

Renovation and reclamation of water bodies was the most expected infrastructural support for all the societies covered under the present study (Table 3). Other infrastructural facilities, viz., crafts and gears, approach road, pump sets and storage facilities recorded the same level of intensity, like that of reclamation of water bodies, for brackishwater and sewagefed societies.

\section{Welfare measure expected}

Housing schemes were the most crucial category of welfare measure expected by the freshwater societies and sewage-fed societies (Table 3). In the case of brackishwater, old age pension ranked as the topmost expectation. Old age pension, health insurance scheme and provident fund for landless agricultural labourers (PROFLAL) alike scheme, were ranked in order of preference under expected welfare measures for freshwater societies.

\section{Policy intervention expected}

Policy intervention in matters of lease rent fixation occupies the top position in the case of all the societies under the study (Table 3 ). The second most important expectation is towards strengthening marketing channels.

\section{Need matrix}

Perceptual mapping of category-wise expected assistances of PFCSs (Table 3), featuring the total frequency for expected fields of assistances, reveal that most of the PFCSs under the present study feel that infrastructural facilities will aid them to perform better. Financial and welfare measures were jointly registered as the second most important expected field of assistance followed by technical assistance in the third and policy interventions in the last positions. Need matrix (Table 3), depicts the intensity of need of categories of expected assistances, as High $(\geq 1.0)$, Medium $(<1.0$ to 0.5$)$ and Low $(<0.5)$. 
Need matrix of fishermen's cooperatives

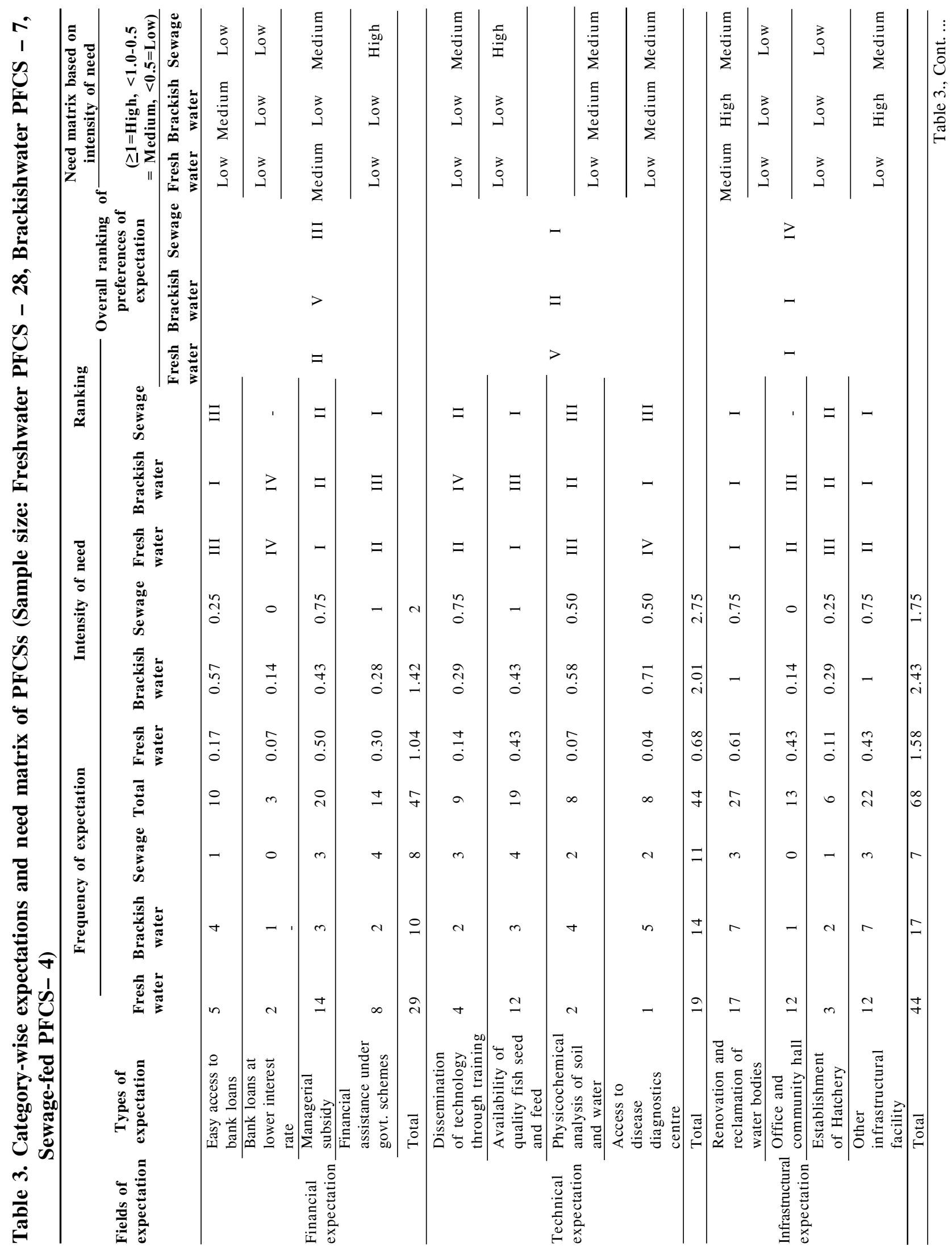




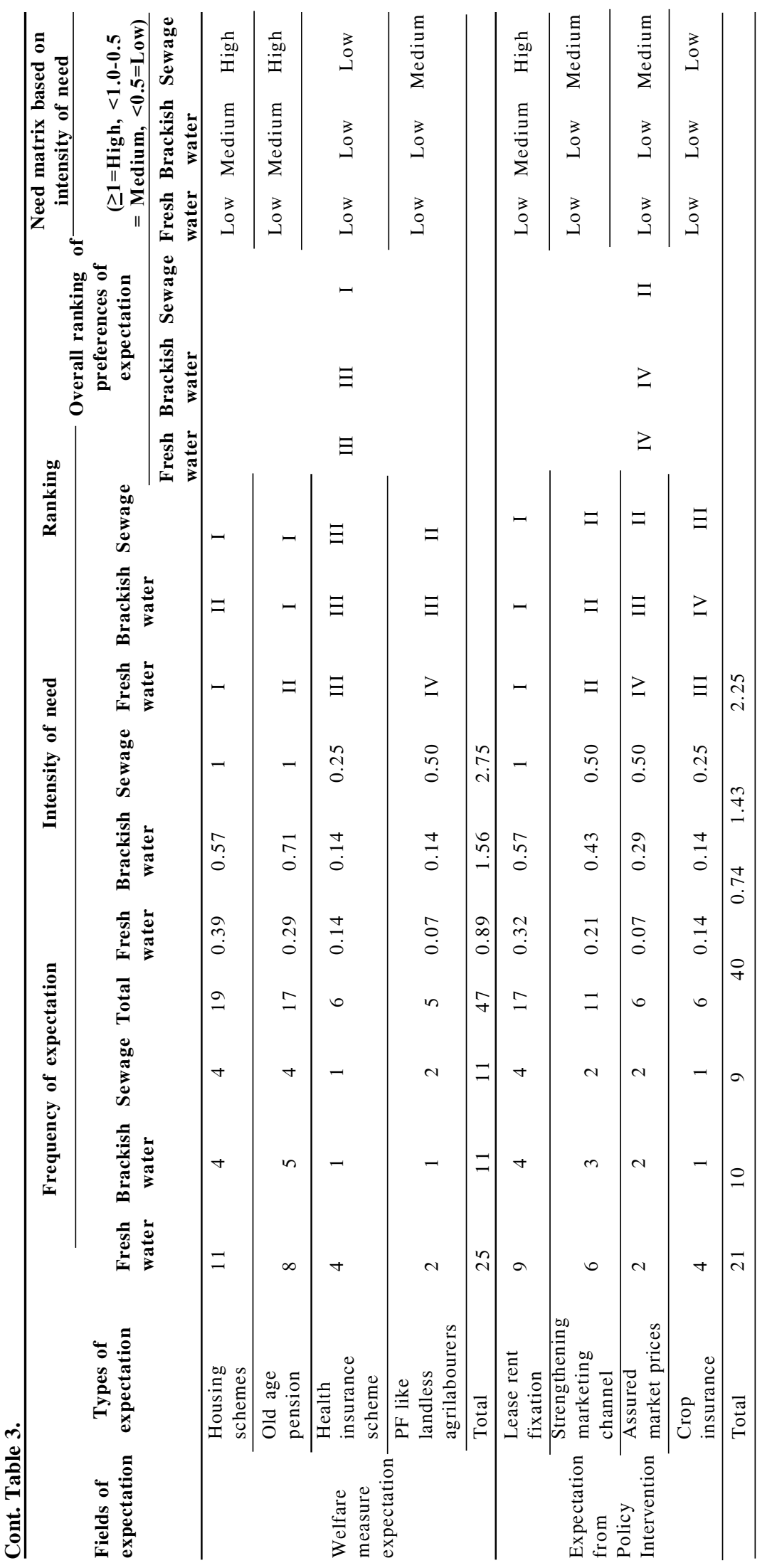




\section{DISCUSSION}

For continued growth in the fishery cooperative sector, it is essential to identify the constraints and extending site-specific needbased support to the PFCSs. Fishery activities in the district under the present study are largely location-specific. The actual needs of PFCSs are imperative for a bottom-up strategy for the development of fisheries. The needs and views of PFCSs aid in strategizing policies for bettering their performances (Pegu et al., 2019). Special thrust is required for understanding the need matrix of target PFCSs for extending any kind of genuine support.

Providing financial assistance to fishermen was one of the main objectives of organizing fishery cooperatives in India. Unfortunately, the financial institutions and cooperative banks have failed to play a role in extending need-based financial support to the fishermen cooperatives (Chandrashekar, 2014). The lack of coordination between financial institutions and cooperative organizations results in inadequate institutional finance which hinders the effective performance of fishery cooperatives (Nair et al., 2007). The finding that availability of requisite finance combined with easy access to credit facility is essential to meet up the rising cost of fishery inputs and overall management of the society agrees with similar studies conducted on economic and financial constraints faced by fishery cooperatives (Nair et al., 2007; Sau et al., 2012; Chandrashekar, 2014; Mahanayak et al., 2017). The maximum intensity of need for financial assistance registered by sewage-fed societies can be explained by the fact that such PFCSs are mostly located in urban vicinity and therefore are more adept in recognizing fisheries as an attractive investment destination. Managerial subsidy registered as lucrative financial assistance by most societies as it is extended as a grant without any condition of repayment.

Fishermen require updated technology skills to compete in a business environment. For the dissemination of technology, training institutes and development agencies need to play an effective role (Sapovadia, 2004). Despite technical and technological support provided by various agencies, PFCSs need more modernized and efficient technical help. Basic and refresher training continually to update technical skills stand out as a prominent need of the fishers. In addition, intensive training for entrepreneurship development (Haldar and Saha, 2015) should be extended to the members of fishermen's cooperatives for enabling them to profit from changing business scenarios. Lack of proper training amongst the cooperative members featured as one of the major constraints involved in the management and operation of the fishery cooperatives in a study by Nair et al. (2007). The result from this study emphasizes the need for training along with regular physicochemical analysis of soil and water, and disease diagnostics as important aspects that reqiure to be addressed for increased production in fishery cooperatives (Bhaumik et al., 1992; Sau et al., 2012; Ghosh and Biswas, 2016; Mahanayak et al., 2017). Availability of quality fish seed and feed at reasonable rates was considered as the most important factor for economically viable culture-based fishery cooperatives and agrees with studies carried out by Bhaumik et al. (1992) and De et al. (2012). With the intensification of aquaculture, there is a growing demand for quantitative and qualitative fish seed and feed, which was blaringly reflected in the study.

Supportive agencies of the central and state governments have been providing funds for infrastructure development for fishery cooperatives (Chandrashekar, 2014). However, PFCSs need support for different items for maintenance, improvement, expansion, diversification and modernization of infrastructure (Table 3). The results based on fishers' perception validate scientists' perception (Nair et al., 2007; Goswami et al., 2013; Chandrashekar, 2014) that the need for infrastructural development is a prerequisite for the proper functioning of fishery cooperatives. 
The emphasis on the need for infrastructural support is in complete agreement with the outcome of the study conducted by Ghosh and Biswas (2016) who suggested that restoration and development of the oxbow lakes in the Ganga river basin will aid in the augmentation of fish production in the fishery cooperatives of the region. Most of the PFCSs in the district are aware that the problem of reduction in fish production in the beels because of siltation can be substantially addressed by reclamation and renovation of these water bodies. The necessity for the establishment of hatcheries expressed by brackishwater and sewage-fed cooperatives will ensure timely availability of quality fish seeds for regular stocking in required numbers and will curtail the recurring cost significantly. Other infrastructural facilities viz., crafts and gears, approach road, pump sets and storage facilities are site-specific and deserve attention on a case-to-case basis.

Supports for fiscal, technical and infrastructural needs to PFCSs assist in community development. Importance of individuals who form communities needs more emphasis than ever before. Individual fishers are poor with low accessibility to the benefits of the developments around them. In this context, it is necessary to take note of fishers' aspirations and needs that will pave the way for designing and implementing welfare measures for their social transformation. Sanitation and health insurance are effective means for bettering the living conditions of fishers through human resource development programmes (Datta and Kundu, 2007). Improvement in their living conditions was aspired through housing schemes by the majority of PFCSs in the district. Most of the PFCSs viewed old-age pension as a likely solution to mitigate the sufferings of old aged fishers. Some of the PFCSs were aware of the PROFLAL scheme for agricultural labourers and expected similar schemes for fisherfolks.

The majority of PFCSs in the study area feel that policies related to lease rent fixation should prioritize the interests of the cooperatives and should not burden them with exorbitant economic rent. Some fishery cooperatives in the country provide complete marketing infrastructure to their members for selling their catch at remunerative prices. The involvement of middlemen in marketing is a major concern that adversely affects the profitability of fishery cooperatives (Nair et al., 2007; Sau et al., 2012). The need for strengthening the marketing channel felt by most PFCSs is in similar lines with the study by Chandrashekar (2014) who suggested that in India cooperative marketing must be developed to ensure fair prices both for producers and consumers.

The need matrix indicated distinct needs concerning the type of society under consideration. Since the culture practice in freshwater, brackishwater and sewage-fed societies vary significantly, their demands vary accordingly. Considering all the societies under the present study, the infrastructural expectation was topmost. This can be attributed to the fact that the majority of the societies are freshwater and dependent on beels for culture practice, which in turn are silted and require renovation for augmenting productivity. Keeping in view the increasing cost of fishery inputs, the majority of PFCSs in North 24 Parganas district being culture-based, call for investment-oriented financial services. The high expectations for welfare measures are due to the fact that fishers, in general, belong to socio-economically backward communities and aspire for improving their living conditions through welfare schemes. The PFCSs seek technical assistance to equip themselves with the latest technologies for enhanced production and resource management. Policy interventions in core matters of lease rent fixation and strengthening of marketing channels for protecting the interest of fishermen's cooperatives were felt by the PFCSs in the district.

The present study has highlighted the needs of the majority of PFCSs in North 24 Parganas district and it emerged in the decreasing order of infrastructural support, financial support, welfare measures, technical support and policy interventions. This investigation suggests that the need matrix of 
PFCSs is imperative for the effective formulation of new schemes and for midcourse correction of ongoing programmes to achieve desired outcomes.

Conflict of interest: Authors have no conflict of interest in this study.

\section{REFERENCES}

Annamalai V, 1996. Return of fishery cooperatives in Maritime states of India. Fish Technology Newsletter, 2(10, 11): 24-30, Available at http:// hdl.handle.net/123456789/3549

Bhaumik U, Pandit PK and KarmakarHC, 1992. Adoption behaviour of fish farmers towards composite fish culture. J Inland Fish Soc India, 24(1): 50-55

Chandrashekar BS, 2014. Fishery co-operative societies in India: Problems and prospects. Global J Res Anal, 3(7): 92-94

Datta SK and Kundu R, 2007. Socio-economic appraisal of culture based fishermen: Case study in West Bengal. J Soc Sci, 15(3): 255-262, doi: 10.1080/ 09718923.2007.11892590

D'cruz ST, 1998. "Impact of Cooperativisation on Artisanal Marine Fishery Sector of Kerala: The Role of Matsyafed". Proceedings of the Symposium on Technological Advancements in Fisheries and its Impact on Rural Development held at Cochin by School of Industrial Fisheries, Cochin University of Science and Technology during December 5-7, 1995, pp 559 -565

De HK, Chattopadhyay DN, Saha GS, Dash AK, Pal S et al., 2012. Strengthening the livelihoods of rural women through polyculture of carps in seasonal ponds. Indian J Fish, 59(3): 137-141

Department of Fisheries, 2019. Handbook of Fisheries Statistics 2017-2018. Directorate of Fisheries, Government of West Bengal, Available in http:/ /dof.gov.in/sites/default/files/2020-08/ HandbookonFS2018.pdf

Directorate of Fisheries, 2017. Directory of PFCS/CFCS in West Bengal 2017. Directorate of Fisheries, Government of West Bengal, pp 284

Ghosh D and Biswas JK, 2016. Socio-economic constraints of a tropical oxbow lake ecosystem in Ganga river basin and strategies for sustainable management. Int J Chem Aqua Sci, 2(3): 1-20

Gopal N, Charles Jeeva J and Pravin P, 2010. Fisheries development agencies and cooperatives in India:

\section{ACKNOWLEDGEMENT}

The authors would like to acknowledge the assistance rendered by the Fishery Officers under the Assistant Director of Fisheries, North 24 Parganas and the office bearers of the Primary Fishermen's Cooperative Societies of the district.

successful interventions towards sustainable fisheries. Fish Chim, 30(7): 47-51

Goswami SN, Patil NG, Chaturvedi A and Hajare TN, 2013. Small scale pond fish farming in a tribal district of India: An economic perspective. Indian J Fish, 60(2): 87-92

Haldar PK and Saha S, 2015. An insight into the performance of fishermen co-operative societies in Tripura. Int J Adv Res Innov Ideas Educ, 1(5): 879-889

Mahanayak B, Chakraborty S and Panigrahi AK, 2017. Preliminary survey on the primary fishermen cooperative societies (PFCS) of Murshidabad district of West Bengal. Indian J Biol, 4 (2): 142-145

Nair SR, Pandey SK, Sharma A and Salim SS, 2007. An evaluation of the business performance of fishery cooperative societies in Vasai Taluk of Thane district, Maharashtra. Indian Coop Rev, pp 224233

Pegu C, Sarkar A, Upadhyay AD, Pal P, Biswas P et al., 2019. Building sustainable communities: A reality check on performance of fishermen's cooperative societies in Tripura, India. Artif Intell Rev, 18(6): 1-12

Planning Commission, 2002. Report of the Working Group on Fisheries for the X Five Year Plan (20022007). Planning Commission, Government of India, pp 63-64

Prakash M, 2000. Role of fisheries cooperatives. Fishcoops, 14(4): 195- 198

Sapovadia, VK, 2004. Fisherman cooperatives: A tool for socio-economic development. International Institute of Fisheries Economics and Trade Conference, July 2004, Japan. Available at https://papers.ssrn.com/sol3/papers.cfm? abstract_id=954986

Sau SK, Sar UK and Patra BC, 2012. Constraints faced by the fishermen cooperative societies of Kharagpur sub-division of Paschim Medinipur district West Bengal. Environ Ecol, 30(3): 501-504

Received - 04.03.2021, Accepted - 11.05.2021, Published-01.06.2021

Section Editor: Prof. T. J. Abraham, Associate Editor 